\title{
Terapia fonoaudiológica em três casos do espectro autístico
}

\section{Language therapy in three cases of autistic spectrum children}

\author{
Juliana Izidro Balestro ${ }^{1}$ Ana Paula Ramos de Souza² ${ }^{2}$ Inaê Costa Rechia ${ }^{3}$
}

\begin{abstract}
RESUMO
O objetivo deste trabalho foi analisar as estratégias terapêuticas fonoaudiológicas em linguagem a partir da visão dialética em sua eficácia e efetividade para que os sujeitos funcionem na linguagem; explicitar alguns dos movimentos terapêuticos necessários para a manutenção do tópico discursivo e de papéis dialógicos pelos sujeitos durante a conversação. Foi realizada análise qualitativa da interação dialógica, antes e após três meses de terapia de linguagem de base dialética, por meio de filmagem e transcrição da interação linguística e não-linguística em 45 minutos de sessão, de três sujeitos do espectro autístico entre seis e oito anos de idade. Os sujeitos ampliaram sua participação dialógica em situações de interação verbal, apresentando progressos no funcionamento da linguagem. Desta forma, é possível afirmar a eficácia e efetividade da abordagem na terapêutica de linguagem em sujeitos do espectro autístico, pois permite perceber o avanço no funcionamento da linguagem. Os movimentos terapêuticos consistem em ancorar as enunciações dos sujeitos atribuindo sentido e mantendo o tópico de discurso.
\end{abstract}

Descritores: Transtorno autístico/terapia; Transtornos da linguagem/terapia; Linguagem

\section{INTRODUÇÃO}

O autismo tem sido descrito por muitos autores, mesmo que num primeiro momento sem essa denominação, desde a década de $30^{(1)}$.

Sabe-se que a terapia fonoaudiológica tem-se apresentado relevante para os sujeitos do espectro autístico, sobretudo quando implementada a partir de reflexões teóricas que hoje estão sob a denominação geral de clínica de linguagem e que trabalham com teorias de linguagem da enunciação e/ou discurso, que tiveram determinação importante na proposta interacionista de Cláudia de Lemos para aquisição da lingua$\mathrm{gem}^{(2)}$. Especialmente no autismo, as alterações de linguagem e comunicação são aspectos sempre presentes no quadro clínico. Várias alterações são descritas tais como alterações qualitativas em interações sociais, na comunicação verbal e não verbal, dificuldades gramaticais e de organização da linguagem, ações

Trabalho vinculado à Universidade Luterana do Brasil - ULBRA - Porto Alegre (RS), Brasil, e à Universidade Federal de Santa Maria - Santa Maria (RS), Brasil.

(1) Pós-graduada em Educação Especial pelo Complexo de Ensino Superior de Cachoeirinha - Cachoeirinha (RS), Brasil; Fonoaudióloga da Escola Especial Novo Horizonte - Porto Alegre (RS), Brasil.

(2) Doutora, Professora Adjunto da Universidade Federal de Santa Maria UFSM - Santa Maria (RS), Brasil.

(3) Pós-graduanda do Programa de Pós-Graduação em Distúrbios da Comunicação Humana da Universidade Federal de Santa Maria - UFSM - Santa Maria (RS), Brasil.

Endereço para correspondência: Juliana Izidro Balestro. R. Adão Pinheiro da Silva, 385, Ipanema, Porto Alegre - RS, CEP 91751-030.

E-mail: jubalestro@hotmail.com

Recebido em: 7/1/2008; Aceito em: 22/8/2008 restritas e esteriotipias verbais e não-verbais, associadas com problemas intelectuais, motores e sensoriais ${ }^{(3)}$.

O interlocutor, em muitos momentos, não consegue interpretar o que a criança autista fala, pois boa parte dessa fala apresenta-se na forma de ecolalia e com interligação difícil com o contexto da conversação. Esses, entre outros motivos, levam a família a buscar o atendimento do profissional de Fonoaudiologia ${ }^{(4-7)}$. No entanto, a presença do fonoaudiólogo ainda é discutida, graças a alguns mal-entendidos em tempos passados, nos quais a intervenção era restrita ao treino da fala ou à abordagem de questões miofuncionais orais. Esse modelo é ressaltado como superado em vários trabalhos de evolução terapêutica de adolescentes e crianças ${ }^{(8-9)}$.

A literatura internacional descreve um grande número de alterações de linguagem e de comunicação nos sujeitos pertencentes ao espectro autístico. Um estudo de corte longitudinal, realizado com tais sujeitos, demonstra haver correlação entre a imitação imediata e gestos protodeclarativos presentes entre três e quatro anos de idade e a linguagem dos sujeitos entre cinco e seis anos e seis meses de idade ${ }^{(10)}$. Outro aponta que o uso de itens lexicais correspondentes a objetos como animais, utensílios da casa, é menos alterado do que o uso de termos temporais, embora haja alterações conceptuais em ambos os tipos de vocabulário ${ }^{(11)}$.

Em relação à comunicação de sujeitos autistas, um estudo realizado na Austrália e na Tailândia demonstrou que, usando ou não a comunicação aumentativa alternativa, a mesma é maior em escolas regulares do que em escolas especiais ${ }^{(12)}$. Esse achado se conecta com a percepção de que as demandas contextuais apresentam papel relevante no desempenho comunicativo de sujeitos autistas, como atesta um estudo de 
caso de um sujeito dos três aos oito anos cujo problema de compreensão se manifestava mais em situações grupais ${ }^{(13)}$.

A proposta terapêutica utilizada nesta pesquisa alinha-se com a visão dialética ${ }^{(2)}$ de aquisição da linguagem, sobretudo a encontrada em trabalhos do interacionismo brasileiro, embora não de modo exclusivo a estes. Nessas visões, antes de focar o domínio de aspectos gramaticais por parte da criança, busca-se identificar as posições discursivas em funcionamento para o sujeito, em termos aquisitivos, e trabalhar com papéis sociais do discurso. Um exemplo da importância da perspectiva discursiva para pensar a relação língua/linguagem são os estudos de aquisição dos pronomeus eu e $t u$. Sabe-se que do ponto de vista cognitivo-linguístico ou gramatical, em uma leitura linguística estrutural, tais pronomes implicam a mudança de posição de referência de falante, ou seja, o $e u$ se refere ao falante atual e o $t u$ ao seu interlocutor. Quando o interlocutor toma o turno, há uma inversão de modo que quem era $e u$ vira $t u$ e vice-versa. Para que tais aspectos gramaticais sejam compreendidos em sua aquisição, é necessária uma leitura discursiva da língua, que não a veja como sistema fechado sem exterioridade, e um entendimento que a linguagem em seu funcionamento demanda também a compreensão de teorias de subjetividade. A ascensão ao campo do imaginário e, a seguir, ao simbólico são passos fundamentais para um funcionamento na linguagem ${ }^{(14-18)}$.

Partindo de tais pressupostos, o presente estudo tem como proposta demonstrar a eficiência e efetividade de uma abordagem interacionista na terapia fonoaudiológica de linguagem de três sujeitos do espectro autístico e explicitar alguns dos movimentos terapêuticos necessários para a manutenção do tópico discursivo e de papéis dialógicos pelos sujeitos durante a conversação.

\section{APRESENTAÇÃO DOS CASOS CLÍNICOS}

\section{Aspectos metodológicos}

Esta pesquisa está inserida no projeto "Padronização de procedimentos para avaliação da linguagem oral de crianças de 1 ano e 6 meses a 5 anos: criação de um protocolo de avaliação fonoaudiológica", aprovado pelo comitê de ética da Universidade Luterana do Brasil sob protocolo 108-2002. Os responsáveis pelos três sujeitos assinaram o termo de consentimento livre e esclarecido para divulgação dos resultados da terapia fonoaudiológica realizada com seus filhos.

O diagnóstico inicial de Transtorno Global do Desenvolvimento foi efetivado pelo neurologista, tomando como base a definição contida no Diagnostic and Statistical Manual of Mental Disorders (DSM) e a definição contida na Classificação Internacional de Doenças (CID). As características utilizadas para identificar tal transtorno são descritas no decorrer da apresentação dos casos, em conjunto com descrições fonoaudiológicas acerca do distúrbio de linguagem dos sujeitos.

Participaram deste estudo três sujeitos, dois do gênero feminino e um do gênero masculino, nascidos e residentes no Rio Grande do Sul com idades entre seis anos e quatro meses e oito anos e quatro meses, estudantes de uma escola especializada em Porto Alegre, aqui identificados por nomes fictícios (Sophia, Agatha, Theo).

Como procedimento inicial para coleta dos dados, foi realizado um contato com a diretora clínica da escola, esclarecendo sobre os procedimentos e objetivos do estudo e solicitado sua autorização. Após a autorização da escola, os pais receberam as explicações sobre a pesquisa e autorizaram a mesma, assinando o termo de consentimento livre e esclarecido. A partir dessa autorização foi marcado um dia para a avaliação individual das crianças mediante filmagem de interação com a terapeuta.

A interação se deu em contexto naturalístico, como prevê a abordagem interacionista ${ }^{(2)}$, em que brinquedos de preferência do sujeito foram utilizados na interação. O objetivo dessa interação inicial era viabilizar a atividade lúdica livre entre terapeuta e sujeito e filmar as interações verbais e não verbais dos mesmos durante os 45 minutos de sessão.

As filmagens foram transcritas e analisadas quanto a aspectos qualitativos da interação, sintonia na comunicação, qualidade gramatical da fala do sujeito (etapa evolutiva de acordo com literatura de aquisição-enunciados de uma palavra, duas ou mais) e interação do sujeito com a terapeuta, por meio de processos dialógicos ${ }^{(17)}$. Durante a intervenção, as sessões foram gravadas em áudio e, a cada 15 dias, filmadas. A filmagem inicial e final de cada sujeito serviram de base para os exemplos apresentados neste artigo.

Os procedimentos terapêuticos incluíram princípios tais como o do sujeito ativo no lúdico permitindo o significado da atividade para si e do funcionamento linguístico como centro da atuação fonoaudiológica em linguagem ${ }^{(14-16)}$. Foram utilizadas estratégias abrangendo a oferta de signos orais (gestos declarativos ou imperativos sobre objetos ou ações acompanhados pela nomeação desses por parte do terapeuta; esboços de produção de fala eram espelhados e melhorados pela terapeuta), de extensão e apoio sintático (as enunciações de sub-elementos da frase eram expandidas pelos seus complementos ou questões pertinentes ao diálogo desenvolvido a partir do brincar incidiam sobre ações) e fonológico (basicamente pelo espelhamento de esboços de produções). Tais estratégias seguem ao princípio de que, mesmo com uma interpretação, muitas vezes duvidosa, não se deve deixar a fala do sujeito à deriva. É importante que se atribua alguma interpretação. Essa interpretação irá permitir um funcionamento linguístico que, aos poucos, poderá introduzir e/ou melhorar o funcionamento linguístico, via processos metafóricos e metonímicos. Ressaltese que isso também foi feito em relação a ecolalias ou estereotipias, que se buscava significar como um não entendimento por parte do interlocutor ou se relacionava a algum contexto de conversação possível na interação lúdica, redirecionando o sujeito para o contexto. Portanto, foram utilizadas estratégias que se ancoraram em trabalhos do campo interacionista ${ }^{(15)}$.

\section{Caso Sophia}

Sophia, primeiro sujeito da pesquisa, gênero feminino, nascida em Porto Alegre, no dia 02/07/1997, oito anos e quatro meses de idade, possui um irmão gêmeo que está na primeira série em um colégio regular, com o qual vive, sob os cuidados da mãe. Os pais se separaram após 18 dias do nascimento prematuro dos filhos. 
Desde os dois anos de idade Sophia apresenta sintomas como estereotipia, problemas de comportamento e obsessões alimentares. Aos quatro anos de idade, entrou para uma escola regular, da qual foi convidada a se retirar por não acompanhar as outras crianças. Atualmente, a menina está recebendo atendimento especializado, todas as tardes, em clínica e escola especializadas em autismo da cidade onde reside. Conta, ao início da terapia, com abordagem diretiva educacional (Método TEACCH), mas não recebe trabalho clínico de linguagem especializado. Ainda tem preferências por determinados alimentos, apresenta estereotipias e linguagem restrita ao início da pesquisa, assemelhando-se ao que se descreve por Síndrome de Asperger na literatura.

A análise qualitativa foi o ponto de partida fundamental para o desenvolvimento de algumas estratégias terapêuticas. Enquanto a menina interagia linguisticamente com a terapeuta, diversas atividades foram desenvolvidas durante os três meses de intervenção fonoaudiológica, tais como: pinturas, contos de histórias, jogos, desenhos, recortes de revistas, colagens, jogos com bola, passeios em praça, entre outras. A idéia central que embasou tais escolhas foi seguir as preferências da menina e, ao mesmo tempo, oportunizar condições de produção discursiva variadas. Durante a terapia com o sujeito, algumas técnicas foram implementadas como: seguir linguisticamente Sophia no decorrer das sessões, deixando-a como atuante principal para construção do vínculo. Outra técnica foi interpretar suas ações, atribuindo-lhes significa- do (tudo que Sophia fazia era narrado pela terapeuta). Um foco importante do trabalho foi a conscientização dos papéis discursivos relacionados às pessoas eu/tu, problematizando sobre quem estava dizendo o que, sobretudo buscando fazê-la assumir um papel discursivo, valendo-se do que se sabe da aquisição típica de linguagem ${ }^{(15)}$. Outro recurso foi utilizar perguntas como: Onde?, Quando?, Com quem? O que você fez?, tanto para fragmentos de estória, caso ou relato, desafiando a menina a responder tais perguntas, baseadas também nos processos dialógicos observados nas conversações adulto-criança ${ }^{(14-16)}$.

Além das ações implementadas nas sessões, buscou-se um contato constante com os pais para incluí-los no processo terapêutico. Infelizmente, não foi possível realizar tal objetivo terapêutico junto à mãe de Sophia. A idéia era conseguir que a mãe se engajasse em conversações com Sophia de modo semelhante ao que se buscava nas sessões, a partir de sua participação em algumas sessões e/ou por entrevistas continuadas.

No Quadro 1 é apresentada parte da transcrição inicial de Sophia, buscando-se destacar momentos da interação para entender seu funcionamento linguístico e a utilização de estratégias terapêuticas.

Segue a última transcrição de Sophia, na qual a terapeuta partiu do enunciado da criança fazendo uma conexão com a estória do Chapeuzinho Vermelho. Após solicita que Sophia conte uma história como uma possibilidade de variar as condições de produção discursiva (Quadro 2).

Quadro 1. Análise inicial de Sophia

\begin{tabular}{|c|c|}
\hline Interação inicial & Data 01/08/2005 \\
\hline 1.J: Me conta que joguinho é esse? & 19.J: Onde posso colocar essa pecinha? \\
\hline 2.S: Shrek & 20.S: (emitiu apenas sons, batendo na mesa e olhando pela janela \\
\hline 3.J: Muito bem! Tu sabe como joga esse joguinho? & em direção oposta ao terapeuta) \\
\hline 4.J: Assim estraga. Me mostra como joga. & 21.J: Nossa! Como tu está bonita hoje! Toda de cor de rosa. \\
\hline 5.J: Ah! É assim, que legal! & 22.S: (risos olhando para o terapeuta) \\
\hline 6.S: Mc lanche & 23.J: Deixa eu ver essas pulseiras? \\
\hline 7.J: Mc lanche? & 24.S: (a menina mostra as pulseiras) \\
\hline 8.J: Tem o brinquedo do Shrek no Mc lanche? & 25.J: Que lindas! Quer ver as minhas? \\
\hline 9.S: /ch/ (olha para o gravador) & 26.S: (mostra que as dela também fazem barulho) \\
\hline 10.J: É um gravador, para gravar a voz, quer ouvir? & 27.J: Que lindas também fazem barulhos! \\
\hline 11.S: Que & 28.S: Rua (olhando para a janela) \\
\hline 12.J: Escuta tua voz então (voltei a fita e mostrei) & 29.J: Posso ver as tuas pulseiras? \\
\hline 13.J: Agora vamos jogar de novo? & 30.S: Não. \\
\hline 14.S: Panamá pé & 31.J: Olha só esse joguinho gira \\
\hline 15.J: Eu não entendi & 32.S: (risos olhando para o jogo) \\
\hline 16.S: Olha a torre (olhando o brinquedo o Shrek) & 33.J: Que legal! \\
\hline 17.J: É uma torre. Sabe pra quê? & 34.S: Fazê \\
\hline \multirow[t]{2}{*}{ 18.J: Oh! Assim! } & 35.J: Faz então, agora é tua vez \\
\hline & 36.S: Ela qué faze \\
\hline Desempenho gramatical e posição discursiva & Estratégias terapêuticas \\
\hline $\begin{array}{l}\text { Sophia em geral se comunica por enunciados de uma palavra, } \\
\text { embora demonstre a compreensão de frases. Pode enunciar frases }\end{array}$ & $\begin{array}{l}\text { Manutenção de tópico via espelhamento e expansão - como ocorre } \\
\text { nas linhas } 6 \text { a } 8 \text { na explanação sobre o jogo do Shrek. }\end{array}$ \\
\hline (linha 16), mas essa produção é rara. Desconecta-se algumas vezes & Mudança de tópico quando a menina apresenta um olhar perdido \\
\hline (linhas $14,20,28$ ) e enuncia sons isolados sobre os quais o outro deve & para a janela (linha28) ou estereotipia (linha 14). \\
\hline Inversão pronominal (linha 36) nunca enunciava o EU. & \\
\hline
\end{tabular}

Legenda: $\mathrm{S}=$ Sophia; $\mathrm{J}=$ terapeuta 
Quadro 2. Análise final Sophia

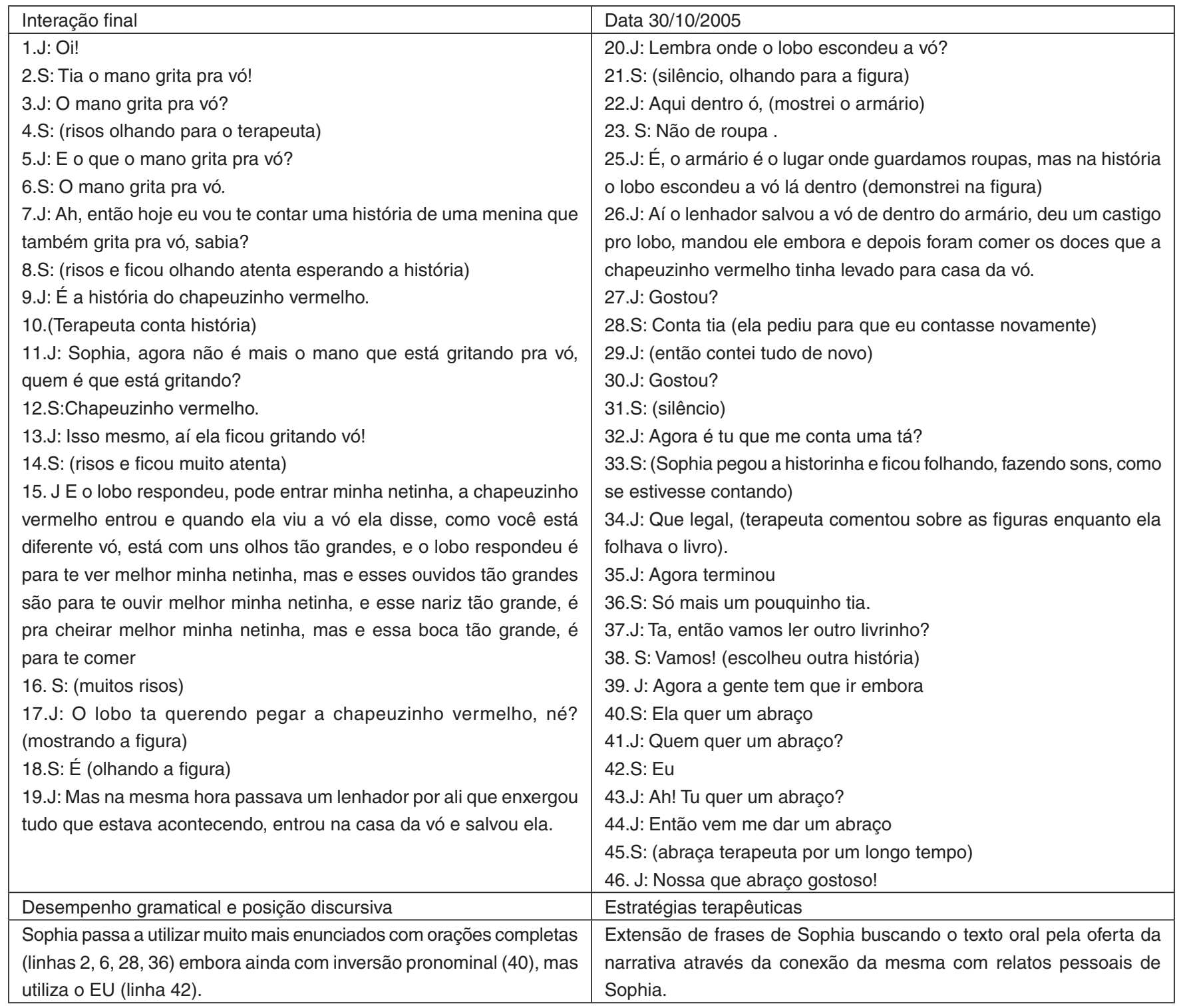

Legenda: $\mathrm{S}=$ Sophia; $\mathrm{J}=$ terapeuta

De acordo com os profissionais da clínica a evolução apresentada surgiu também nos contextos da clínica com outros interlocutores, o que possibilitou pensar a inclusão de Sophia no ensino regular.

\section{Caso Agatha}

O sujeito 2 da pesquisa, codinome Agatha, gênero feminino, nascida em Porto Alegre, no dia 04/03/1998, sete anos e oito meses de idade. Agatha vive com os pais, uma irmã de dez anos, que está na quarta série em uma escola regular e um irmão mais novo, que assim como ela, também tem o diagnóstico de transtorno global do desenvolvimento dentro do espectro autístico. O parto foi normal e ocorreu sem complicações, a menina engatinhou aos oito meses e caminhou aos 13 meses, a mãe refere que, quando bebê ao se cortar ou se machucar a menina parecia não sentir dor, pois não chorava. Os pais perceberam os primeiros sintomas de anormalidade por volta de um ano e seis meses de idade. Relatam que sua linguagem era ininteligível, que a menina basicamente repetia palavras e frases principalmente de personagens de desenhos infantis, que imitava os sons de animais, não brincava com outras crianças e também que se alterava com mudanças em sua rotina. Atualmente, Agatha está em inclusão em uma escola regular pela manhã e à tarde frequenta uma clínica especializada.

No Quadro 3 estão apresentadas as interações iniciais e finais de Agatha.

Durante o processo terapêutico, com atividades semelhantes às de Sophia, também foram utilizadas técnicas para conscientização do ritmo e inteligibilidade de fala tais como a de "sobrearticulação" na qual se buscou o exagero da excursão dos lábios, língua e mandíbula durante movimentos articulatórios para aumentar a clareza articulatória. Um dos focos principais foi no uso do eu/tu e perguntas como: Onde?, Quando?, Com quem? O que você fez?, baseadas, também, nos processos dialógicos. 
Quadro 3. Análises inicial e final de Agatha

\begin{tabular}{|c|c|}
\hline Interação inicial - Data: 01/08/2005 & Interação final - Data: 31/10/2005 \\
\hline 1.J: Olha aqui! & 1. J: Oi Agatha! \\
\hline 2.A: (repete a fala da terapeuta) & 2. A: Oi! \\
\hline 3.J: Tu sabe quem é esse aqui? & 3. J: Vamos ler uma historinha hoje? \\
\hline 4.A: (repete a fala da terapeuta)... & 4. A: (repete a fala da terapeuta) \\
\hline 15.J: Isso é o gravador para gravar nossa voz. Quer ver aqui é o & 5. J: Escolhe uma então \\
\hline microfone Oh! Meu nome é Juliana. & 6. A: Da pinseja (a menina olhou todos os livros antes de escolher) \\
\hline 16.A: Peu nome é Joana (a menina pega o gravador e imita gesto e & 7. J: Essa da princesa \\
\hline fala da terapeuta) & 8. J: (terapeuta conta início história) \\
\hline 17.J: Teu nome é Juliana? Como é o teu nome? & 9. A: Pinseja, vassora, buxa (referiu-se para madrasta) \\
\hline 18.A: (repete a fala da terapeuta) & 10. Isso! Muito bem! \\
\hline 19.A: Nome? & 11. (terapeuta conta o resto da história) \\
\hline 20.J: Como é que é teu nome? & 12. A: Fada, pinseja, vetido, sapato \\
\hline 21.A: (primeiro repete a fala da terapeuta depois responde) é & 13. A: Essa gato bota \\
\hline Agatha & 14. J: Oba tu vai ler pra mim a do gato de botas, eu adoro. \\
\hline 22. J: Isso é Agatha & 15. A: Ea uma vez \\
\hline 41.Grabador história & 16. A: O gato e o pincipe, e o castelo \\
\hline 42.J: Então conta uma história pra gente gravar & 17. A: (silêncio) \\
\hline 43.A: Alô. Que que é isso aqui? (pegou uma caixa de figuras e & 18. J: Que legal! E aí o que aconteceu? \\
\hline perguntou o que era) & 19. A: E o gato e bota (depois fala ficou acelerada e ininteligível) \\
\hline 44.J: O que tu acha que é? & (terapeuta assite Agatha para contar até o final) \\
\hline 45.A: Pitz, socoate. & \\
\hline 46.J: Isso mesmo é uma pizza de chocolate & \\
\hline Desempenho gramatical e posição discursiva & Estratégias terapêuticas \\
\hline $\begin{array}{l}\text { Agatha faz muitas ecolalias (exs. } 1 \text { a } 4 \text { ) e não consegue ocupar a } \\
\text { posição de EU (linha 21). Produz enunciados de uma a duas palavras } \\
\text { (linhas } 41,45 \text { ) }\end{array}$ & $\begin{array}{l}\text { Na primeira transcrição atribuição de sentido às ecolalias (linhas } 15 \\
\text { a } 20 \text { da interação inicial). Esse reconhecimento com a expansão de } \\
\text { enunciados (linha 46). Na final, ocorre a busca do desenvolvimento } \\
\text { narrativo, por assistência à produção de histórias. }\end{array}$ \\
\hline
\end{tabular}

Legenda: $A=$ Agatha; $J=$ terapeuta

\section{Caso Theo}

O sujeito 3, codinome Theo, gênero masculino, nascido em Porto Alegre, no dia 27/07/1999, seis anos e quatro meses de idade, vive com os pais e duas irmãs mais velhas, uma delas é Agatha, sujeito 2 desta pesquisa. O parto foi normal e ocorreu sem complicações, o menino engatinhou aos sete meses e caminhou com um ano e dois meses. A mãe refere ter sido um bebê sereno e que, muitas vezes, não manifestava seus desejos quanto à alimentação e situações desconfortáveis. Os pais perceberam seu comprometimento por volta dos dois anos, pois relatam que o filho apresentava comportamentos diferentes das crianças normais, e parecidos com os da irmã (Agatha), como fixações por personagens de desenhos infantis, não brincava com outras crianças, e que se alterava com mudanças em sua rotina. Atualmente, Théo, assim como Agatha, está em inclusão em uma escola regular pela manhã e, à tarde, frequenta uma clínica, onde recebe atendimento especializado (Quadro 4).

Tanto para Theo quanto para Agatha obteve-se uma intervenção mais eficaz junto à família, já que a mãe e o pai passaram a acreditar mais no potencial comunicativo dos filhos e a investir mais no diálogo. Perceberam a evolução e referiram que a mesma se deu na clínica e em outros espaços sociais (nova escola, ambientes de lazer). Também foi observado que os pais de Theo e Agatha ficaram mais abertos, durante a terapia de linguagem, a discussões de questões subjetivas com o setor de Psicologia da clínica.

\section{DISCUSSÃO}

Na observação dos três casos, a proposta interacionista implementada demonstrou-se efetiva para o surgimento de uma posição discursiva mais adequada às necessidades funcionais da conversação. $\mathrm{O}$ uso do pronome e $u$ que começa a surgir nos casos de Sophia e Agatha, e se reforça no caso de Theo, demonstra evolução importante em termos de estruturação do sujeito na linguagem. Nesse sentido, pode ser observado que a proposta de clínica de linguagem ${ }^{(2)}$ pôde produzir um bom efeito clínico em linguagem. Esse fato pode ser comprovado na análise qualitativa da linguagem nas interações que evidenciaram a passagem do período gramatical de análise sintática para o período narrativo ${ }^{(14-16)}$.

Os três sujeitos apresentavam, ao início da terapia, várias características do ponto de vista da descrição gramatical adequadas ao período de domínio das relações sintagmáticas. $\mathrm{O}$ aparente domínio lexical pela enunciação adequada de alguns signos não se concretizava em um funcionamento suficiente na conversação para que suas enunciações fossem interpretadas com sucesso pelo interlocutor. Esses aspectos confirmam as descrições de alterações pragmáticas realizadas em vários estudos com sujeitos do espectro autístico ${ }^{(4-6,9,12)}$. 
Quadro 4. Análises inicial e final de Theo

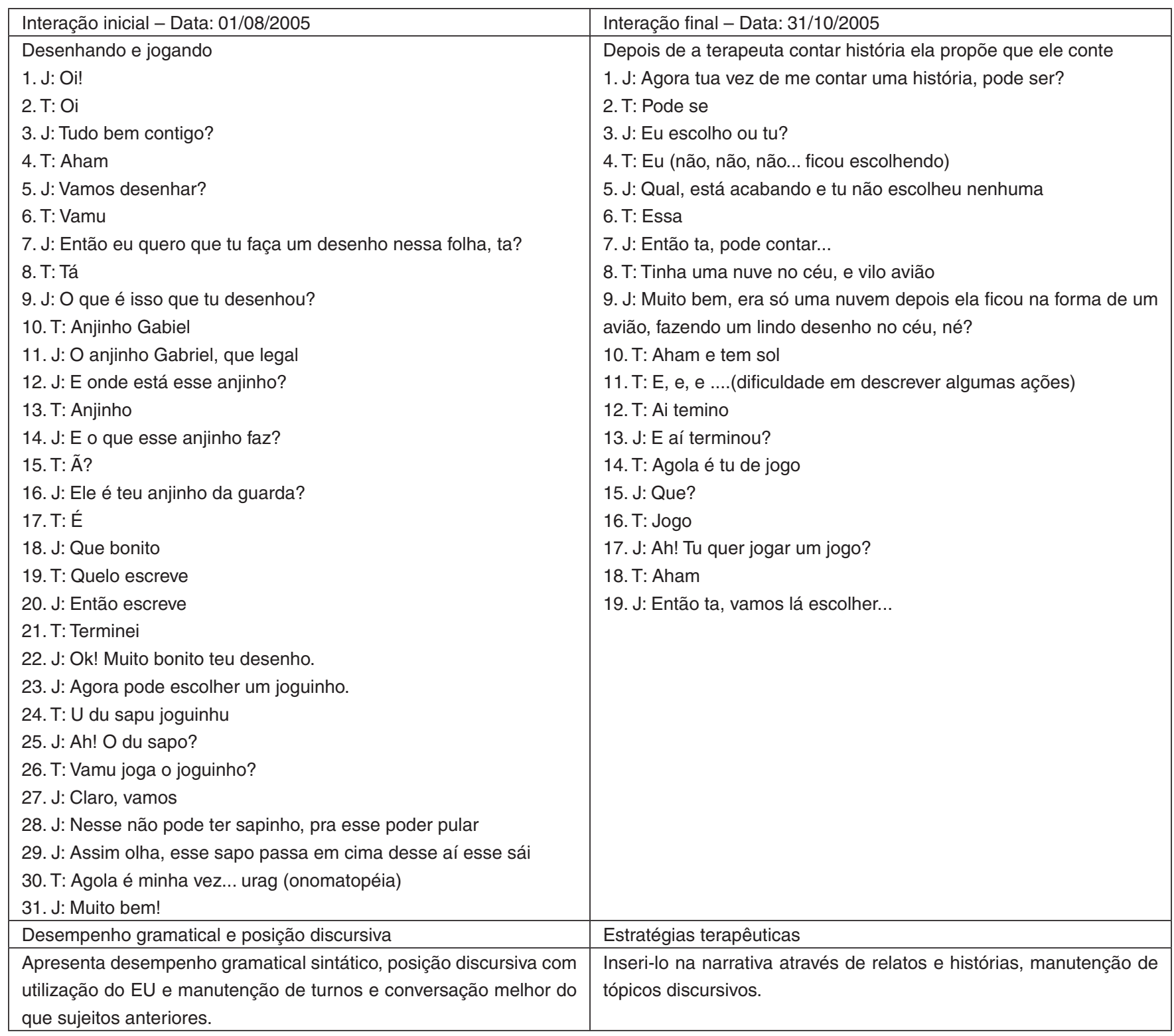

Legenda: $\mathrm{T}=$ Theo; $\mathrm{J}=$ terapeuta

Tais apontamentos justificam o fato de ambas as meninas terem dificuldade no uso do pronome $e u$ e na aquisição da habilidade de narrar. Enquanto o primeiro aspecto exige uma estruturação subjetiva do self $*(18)$, o segundo demanda uma atenção compartilhada e o poder imaginativo, ambos os aspectos descritos na literatura como de difícil organização no espectro autístico ${ }^{(1,12)}$.

A análise qualitativa dos casos apresenta o funcionamento de linguagem de cada sujeito, sobre o qual a terapeuta deverá refletir para poder criar estratégias de conexão singulares. Essa conexão demanda um lançar-se efetivamente no diálogo, fazendo, como no caso de Sophia, um grande esforço para manter a conversação e exercer o princípio de cooperação entre interlocutores, para viabilizar que a linguagem se transforme numa ação sobre o mundo e sobre outro ${ }^{(2,15-16)}$. Para tanto, o terapeuta deverá proporcionar e aproveitar os diversos espaços sociais possíveis para produzir discursos, como a terapeuta desta pesquisa fez. Ao trazer situações como passeios a lanchonetes conhecidas, jogos relacionados aos passeios, relato de vida pessoal e pôde conectá-los a vivências ou a diálogos nas sessões, bem como narrativas ficcionais. Um exemplo é o enunciado presente no Quadro 2 de Sophia no qual ela enuncia "Tia a vó grito com o mano" na linha 2 e esse fato é conectado com a história que a terapeuta conta a seguir.

Em relação ao acesso das famílias e sua inclusão na terapêutica, o que ocorreu nos casos de Agatha e Theo, mas não no de Sophia, faz-se necessária uma reflexão ${ }^{(17)}$ sobre a terapia da criança, muitas vezes, anteceder um momento de tomada de consciência dos pais da necessidade de buscarem auxílio psicológico. Esse fato talvez explique a resistência da mãe de Sophia

*O termo self não tem boa tradução em português. Por isso, mantém-se o original proposto por Winnicott (2000) cuja melhor aproximação é "ser" 
às entrevistas, em oposição à ausência de resistência por parte dos pais de Theo e Agatha. Estes foram mais permeáveis a discussões subjetivas com o setor de psicologia da clínica. Assim, os casos demonstram que a família pode ser determinante na evolução do sujeito e que não é sem motivo que Sophia também apresente um desenvolvimento inicial e evolução terapêutica mais restrita do que Agatha e Theo, pois os determinantes sociais e psíquicos são inquestionáveis na sua relevância para inserir o sujeito em um funcionamento linguístico.

\section{CONCLUSÃO}

Os casos analisados demonstraram a eficácia da abordagem interacionista na terapêutica de linguagem dos sujeitos e que a avaliação qualitativa de base observacional é, sem dúvida, extremamente rica para o planejamento terapêutico, pois permite identificar pontos possíveis de sintonia com o sujei- to, para poder proporcionar o funcionamento dos processos metafóricos e metonímicos.

O movimento constante que a terapeuta faz de resgate de enunciados que, num primeiro momento, estão à deriva, permite observar uma manutenção da conversação crescente por parte dos sujeitos autistas, com diminuição de jargões e aumento do uso do pronome $e u$, dois sinais que considerados elucidativos de progresso linguístico e subjetivo.

Por meio da investigação do surgimento e do aumento dos processos dialógicos na linguagem, os sujeitos apresentaram evolução positiva. Entretanto, apesar de todo o desenvolvimento linguístico referente aos processos dialógicos e ao discurso narrativo, as crianças estudadas ainda se mostraram dependentes do papel estruturante do terapeuta para se manter em conversação, não tendo adquirido a autonomia discursiva. No entanto, demonstram sinais importantes de que uma autonomia maior é possível com a sequência do trabalho terapêutico.

\begin{abstract}
The aims of this study were to analyze the intervention strategies on language based on the dialectic view of its efficiency and effectiveness to change the subjects' manifested language, and to evidence some of the therapeutic movements needed to maintain the discursive topic and the dialogic roles during conversation. It was conducted a qualitative analysis of the dialogic interaction carried out before and after three months of therapy based on the dialectic method. The 45-minute sessions of three subjects within the autistic spectrum with ages between six and eight years were recorded and its transcriptions were analyzed. It was observed that the subjects expanded their dialogic roles, presenting progress on language functioning. Therefore, it's possible to emphasize the efficacy and effectiveness of the therapeutic approach used, for it allowed the accompaniment of language progresses. Therapeutic movements consist in anchoring the subjects enunciations by providing them sense, and maintaining the discursive topic.
\end{abstract}

Keywords: Autistic disorder/therapy; Language disorders/therapy; Language

\section{REFERÊNCIAS}

1. Tustin F. Estados autísticos em crianças. Rio de Janeiro: Imago; 1984.

2. Palladino RRR. Desenvolvimento da linguagem. In: Ferreira LP, BefiLopes D, Limongi SCO, organizadores. Tratado de fonoaudiologia. São Paulo: Editora Roca; 2004. p. 762-71.

3. Klecan-Aker JS, Gill C. Teaching language organization to a child with pervasive developmental disorder: a case study. Child Lang Teach Ther. 2005;21(1):60-74.

4. Cardoso C, Fernandes FDM. Uso de funções comunicativas interpessoais e não interpessoais em crianças do espectro autístico. Pró-Fono. 2003;15(3):279-86.

5. Cardoso C, Fernandes FDM. Relação entre os aspectos sócio cognitivos e perfil funcional da comunicação em um grupo de adolescentes do espectro autístico. Pró-Fono. 2006;18(1):89-98.

6. Barros CGC, Ferreira VG, Friche CP, Ribeiro MHB, Pratezi ACC. Atividade de vida prática: suas contribuições para o desenvolvimento da semântica e pragmática em portadores da Síndrome de Asperger. J Bras Fonoaudiol. 2005;5(23):361-8.

7. Fernandes FDM. Terapia de linguagem em crianças com transtornos do espectro autístico. In: Ferreira LP, Befi-Lopes DM, Limongi SCO, organizadores. Tratado de fonoaudiologia. São Paulo: Editora Roca; 2004. p.941-53.

8. Fernandes FDM. Resultados de terapia fonoaudiológica com adolescentes com diagnóstico inserido no espectro autístico. Pró-Fono. 2005;17(1):67-76.

9. Miilher LP, Fernandes FDM. Análise das funções comunicativas expressas por terapeutas e pacientes do espectro autístico. Pró-Fono. 2006;18(3):239-48.

10. Toth K, Munson J, Meltzoff AN, Dawson G. Early predictors of communication development in young children with autism spectrum disorder: joint attention, imitation, and toy play. J Autism Dev Disord. 2006;36(8):993-1005.

11. Perkins MR, Dobbinson S, Boucher J, Bol S, Bloom P. Lexical knowledge and lexical use in autism. J Autism Dev Disord. 2006;36(6):795-805.

12. Chiang HM, Lin YH. Expressive communication of children with autism. J Autism Dev Disord. 2008;38(3):538-45.

13. Wagner CR, Nettelbladt U. Tor: case study of a boy with autism between the age of three and eight. Child Lang Teach Ther. 2005;21(2):123-45.

14. Issler DS. A aquisição do "eu e tu" na relação mãe-criança: intersecções entre a linguística e a psicologia. Letras Hoje. 1997;32(4):81-106

15. Maldonade IR. Erros na aquisição da flexão verbal: uma análise interacionista [tese]. Campinas: Universidade Estadual de Campinas; 2003.

16. Carvalho G, Avelar T. Linguagem e autismo: fatos e controvérsias [Internet]. [citado 2007 Jul 7]. Disponível em: http://www.proext.ufpe. br/cadernos/saude/autismo.htm.

17. Vorcaro A. A clínica psicanalítica e fonoaudiológica com crianças que não falam. Distúrb Comum. 2003;15(2):265-87.

18. Winnicott DW. Da pediatria à psicanálise: obras escolhidas. Rio de Janeiro: Imago; 2000 